\title{
Syntheses and Properties of Silicon-containing, Soluble and Fully Aromatic Polymers
}

\author{
Shota Nishimura ${ }^{1,2}$, Eiichi Akiyama ${ }^{1}$, Yu Nagase $^{2}$ \\ ${ }^{1}$ Sagami Chemical Research Institute, 2743-1 Hayakawa, Ayase, Kanagawa 252-1193, Japan \\ Fax: +81-467-77-4113,*e-mail: akiyama@sagami.or.jp \\ ${ }^{2}$ Tokai University, 4-1-1 Kitakaname, Hiratsuka, Kanagawa 259-1292, Japan
}

In order to obtain excellently heat-resistant and transparent polymer materials, the fully aromatic polysilarylenesiloxanes were synthesized via the solution polymerization and the melt-condensation from the corresponding disilanol monomer. And the thermal properties of these polymers were investigated by using DSC and TGA. The polymer synthesized via the solution polymerization showed good solubility in various organic solvents, and $116^{\circ} \mathrm{C}$ of glass transition temperature, $T_{\mathrm{g}}$, and $529^{\circ} \mathrm{C}$ of $5 \%$ weight loss temperature, $T_{\mathrm{d} 5}$. On the other hand, the product obtained by the melt-condensation polymerization partially dissolved in organic solvent, and showed $93^{\circ} \mathrm{C}$ of $T_{\mathrm{g}}$. Polyaryleneoxysiloxane was also prepared from 4,4'-dihydroxytetraphenylmethane and dichlorodiphenylsilane, and showed $137^{\circ} \mathrm{C}$ of $T_{\mathrm{g}}$, while polyaryleneoxysiloxane was easily hydrolyzed in homogeneous solution containing a base etc.

Key words: Fully aromatic polymer / Polycondensation / Solubility / Thermal property / Transparence

\section{INTRODUCTION}

Polysilarylenesiloxanes and their copolymers have been investigated as high temperature elastomers [1]. For example, poly (tetramethyl- $p$ silphenylenesiloxane), PTMPS, of a typical polysilarylenesiloxane showed melting temperature, $T_{\mathrm{m}}$, of $135^{\circ} \mathrm{C}$, glass transition temperature, $T_{\mathrm{g}}$, of $-20^{\circ} \mathrm{C}$ and thermal degradation temperature, $T_{\mathrm{d}}$, of $411^{\circ} \mathrm{C}$ [2-6]. If a new type of polysilarylenesiloxane showing a higher $T_{\mathrm{g}}$ or $T_{\mathrm{m}}$ than PTMPS is obtained, it is possible that the polysilarylenesiloxane is applied to such heat-resistant materials. In previous studies, we had reported fully aromatic polysilarylenesiloxane having tetraphenyldisiloxane units instead of tetramethyldisiloxane units, which showed high $T_{\mathrm{m}}$ over $300^{\circ} \mathrm{C}$ and no solubility in common solvents [6]. On the other hand, because of insoluble fully aromatic polysilarylenesiloxanes, melt-polycondensation of the corresponding disilanol monomers had be conducted to successfully prepare insoluble and amorphous films [7]. Soluble and fully aromatic polymer having short $\pi$-conjugation length would be expected to apply to transparent and heat-resistance material.

In this paper, polysilarylenesiloxanes were prepared via polycondensation in solvent, and melt-polycondensation from bis( $p$-(hydroxyldiphenylsilyl)phenyl) ether (P1 and P2 in Scheme I). Fully aromatic polyaryleneoxysiloxane was also prepared from 4,4'-dihydroxytetraphenylmethane and dichlorodiphenysilane, based on the similar concept of soluble and fully aromatic silicon-containing polymer (P3 in scheme II). The thermal properties of the obtained polymers were investigated by using the thermogravimetric analysis, TGA, and differential scanning calorimetry, DSC. To investigate the process of the melt-polycondensation in detail, the volatile compounds generated during the reaction was analyzed by means of a GC-MS, and the difference of chemical structures between P1 and P2 was investigated by using ${ }^{13} \mathrm{C}$-NMR spectra.

\section{EXPERIMENTAL}

2.1 Materials

Magnesium savings, bis( $p$-bromophenyl) ether, toulene, tetrahydrofuran (THF) and anhydrous sodium sulfate were obtained from Wako Pure Chemical Ind. Trichlorosilane, 4,4'-dihydroxytetraphenylmethane, DTM, and N,N-dimethyl-4aminopyridine (DMAP) were provided from Tokyo Chemical Ind. Bromobenzene, $n$-hexane, benzene, diethyl ether and pyridine were purchased from Kanto Chemical Ind. 5 wt.\% palladium on activated carbon was purchased from Sigma-Aldrich. Dichlorodiphenylsilane, DDS, was purified by distillation before use. Tetramethylguanidinium di-2-ethylhexanoate was prepared by mixing tetramethylguanidine and 2-ethylhexanoic acid in 1:2 molar ratio for several days. Chlorodiphenylsilane was prepared according to the literature [8].

\subsection{Characterizations}

${ }^{1} \mathrm{H}-\mathrm{NMR}$ spectra and ${ }^{13} \mathrm{C}-\mathrm{NMR}$ spectra were recorded on a Bruker DPX-250 spectrometer and a Bruker DRX-500 spectrometer, respectively. IR spectra were recorded with Horiba FT-720 equipped with SensIR technologies DuraSampl IRII. High performance liquid chromatography (HPLC) analysis was conducted with a Waters 2690 by using $\mathrm{THF} / \mathrm{CH}_{3} \mathrm{CN}(20 \mathrm{v} / \mathrm{v} \%)$ as an eluent, equipped with a column of ODS-3. GPC analysis was conducted with a Tosoh GPC-8020 by using THF as SuperH5000, 3000, 2000, and 1000. Standard polystyrenes were used for a calibration. Gas chromatography-mass spectrometry, GC-MS, was conducted with Shimadzu GC-MS QP2010. UV-Vis absorbance spectra were 
measured with Hitachi U-1800.

\section{3 $\operatorname{Bis}(p$-(diphenylsilyl)phenyl) ether (1)}

A solution of bis( $p$-bromophenyl) ether (24.8 g, $76.0 \mathrm{mmol})$ in THF $(300 \mathrm{~mL})$ was added slowly dropwise to mixture of magnesium savings $(7.38$ $\mathrm{g}, 304 \mathrm{mmol}$ ) activated by 1,2-dibromoethane and chlorodiphenylsilane $(31.6 \mathrm{~g}, 144 \mathrm{mmol})$ in THF $(120 \mathrm{~mL})$ under an argon atmosphere at $0^{\circ} \mathrm{C}$. After stirring at $50^{\circ} \mathrm{C}$ for $16 \mathrm{~h}$, the reaction mixture was washed with water. The precipitated salts were removed by filtration with Celite. The filtrate was extracted with diethyl ether, and purified by column chromatography on silica gel with $n$-hexane as eluent to afford $\mathbf{1}(9.24 \mathrm{~g})$ as a colorless waxy solid. Yield: $22.7 \% . T_{\mathrm{m}}=65^{\circ} \mathrm{C}$. ${ }^{1} \mathrm{H}-\mathrm{NMR}, \mathrm{d}\left(250 \mathrm{MHz}, \mathrm{ppm}, \mathrm{CDCl}_{3}\right): 5.47(\mathrm{~s}, 2 \mathrm{H})$, $7.04(\mathrm{~d}, 4 \mathrm{H}, J=8.50 \mathrm{~Hz}), 7.34-7.43(\mathrm{~m}, 12 \mathrm{H})$, 7.52-7.60 (m, 12H). IR, $v\left(\mathrm{~cm}^{-1}\right.$, reflect $): 2140(\mathrm{~m}$, $\mathrm{Si}-\mathrm{H}), 1577(\mathrm{~m}, \operatorname{arC}=\mathrm{C}), 1490(\mathrm{~m}, \operatorname{arC}-\mathrm{C}), 1427$ (m), 1224 (m, C-O-C), 1174 (m, C-O-C), 1110 (s, Si-Ar), 794 (s), 727 (s), 694 (s).

2.4 Bis(p-(hydroxydiphenylsilyl)phenyl) ether (2) Water $(1.54 \mathrm{~mL}, 85.5 \mathrm{mmol})$ and THF $(14.0 \mathrm{~mL})$ were added to a flask which charged 5 wt.\% palladium on activated carbon $(735 \mathrm{mg}, \mathrm{Pd}: 346$ $\mu \mathrm{mol})$ was dried in vacuo and filled with argon. 1 $(9.14 \mathrm{~g}, 17.1 \mathrm{mmol})$ in THF $(14.5 \mathrm{~mL})$ added dropwise to the flask. The mixture was stirred at $50^{\circ} \mathrm{C}$ for $2.5 \mathrm{~h}$. The catalyst was filtered off, and the solvent was removed. The crude was purified by recrystallization from benzene solution to obtain $2(7.89 \mathrm{~g})$ as a white powder. Yield: $96.5 \%$ (HPLC purity: $99.0 \%$ ). $T_{\mathrm{m}}=173^{\circ} \mathrm{C} .{ }^{1} \mathrm{H}-\mathrm{NMR}, \mathrm{d}$ $\left(250 \mathrm{MHz}, \mathrm{ppm}, \mathrm{CDCl}_{3}\right): 2.49(\mathrm{~s}, 2 \mathrm{H}),, 7.05(\mathrm{~d}$, $4 \mathrm{H}, J=8.50 \mathrm{~Hz}), 7.26-7.45(\mathrm{~m}, 12 \mathrm{H}), 7.58-7.65$ $(\mathrm{m}, 12 \mathrm{H}) . \mathrm{IR}, v\left(\mathrm{~cm}^{-1}\right.$, reflect $): 3268(\mathrm{bw}, \mathrm{Si}-\mathrm{OH})$, $1579(\mathrm{~m}, \operatorname{arC}=\mathrm{C}), 1492(\mathrm{~m}, \operatorname{arC}-\mathrm{C}), 1427(\mathrm{~m})$, 1238 (s, C-O-C), 1174 (s, C-O-C), 1116 (vs, Si-Ar), 821 (vs, Si-OH), 696 (vs). 2 was further purified by recrystallization twice just before use.

\subsection{Polymerizations (typical procedures)}

$2(610 \mathrm{mg}, 1.07 \mathrm{mmol})$ was refluxed for $24 \mathrm{~h}$ in toluene $(1.00 \mathrm{~mL})$, in the presence of a few drops of tetramethylguanidinium di-2-ethylhexanoate as a catalyst using an azeotropic trap to remove water. The mixture was poured into an excess amount of methanol to obtain P1 (296 mg) as a white fibrous. Yield: $48.6 \% . M_{\mathrm{n}}=4.40 \times 10^{4}, M_{\mathrm{w}}=$ $8.23 \times 10^{4}\left(M_{\mathrm{w}} \cdot M_{\mathrm{n}}{ }^{-1}=1.87\right)$. IR, $v\left(\mathrm{~cm}^{-1}\right.$, reflect $)$ : $1579(\mathrm{~m}, \operatorname{arC}=\mathrm{C}), 1490(\mathrm{~m}, \operatorname{arC}-\mathrm{C}), 1427(\mathrm{~m})$, 1238 (m, C-O-C), 1174 (m, C-O-C), 1114 (s, Si-Ar), 1049 (bs, Si-O-Si), 697 (vs).

$2(80.0 \mathrm{mg}, 0.141 \mathrm{mmol})$ was charged into a glass tube and heated at $400^{\circ} \mathrm{C}$ for $7 \mathrm{~h}$ under 80 $\mathrm{kPa}$ to afford $\mathbf{P 2}(50.0 \mathrm{mg})$ as a white powder. The volatile compounds were trapping in a glass vessel cooled by frozen $\mathrm{CO}_{2}$ during meltpolycondensation. IR, $v\left(\mathrm{~cm}^{-1}\right.$, reflect): $1718(\mathrm{w})$, $1581(\mathrm{~m}, \operatorname{arC}=\mathrm{C}), 1489(\mathrm{~m}, \operatorname{arC}-\mathrm{C}), 1429(\mathrm{~m})$, 1115 (s, Si-Ar), 1026 (bs, Si-O-Si), 696 (s).

DDS (3.57 g, $14.1 \mathrm{mmol})$ was added slowly dropwise to DTM (3.00 g, $8.51 \mathrm{mmol})$ and DMAP $(0.11 \mathrm{~g}, 0.90 \mathrm{mmol})$ and pyridine $(1.50 \mathrm{~mL}, 18.6$ $\mathrm{mmol})$ in toluene $(8.50 \mathrm{~mL})$ under an argon atmosphere. Then reaction temperature was elevated gradually to refluxing temperature. After stirring for $24 \mathrm{~h}$, the mixture was poured into an excess amount of solution (methanol/acetone = $4 / 1$ in vol. ratio) to obtain $\mathbf{P 3}$ (2.99 g) as a white powder. Yiled: $75.1 \% . M_{\mathrm{n}}=1.84 \times 10^{4}, M_{\mathrm{w}}=$ $6.09 \times 10^{4}\left(M_{\mathrm{w}} \cdot M_{\mathrm{n}}^{-1}=3.31\right)$. IR, $v\left(\mathrm{~cm}^{-1}\right.$, reflect $)$ : $1602(\mathrm{~m}, \operatorname{arC}=\mathrm{C}), 1500(\mathrm{~s}, \operatorname{arC}-\mathrm{C}), 1236(\mathrm{~s}), 1176$ (s, C-O), 1126 (m, Si-Ar), 926 (bs, Si-O-Ar), 827 (s), 696 (vs).

\subsection{Thermal analysis}

TGA was performed by using a SII Nano Technology TG/DTA6200 at a heating rate of $10^{\circ} \mathrm{C} \cdot \mathrm{min}^{-1}$ under argon flow $\left(100 \mathrm{~mL} \cdot \mathrm{min}^{-1}\right)$. Differential scanning calorimetry, DSC, was performed by using a SII Nano Technology DSC6220 at a heating rate of $10^{\circ} \mathrm{C} \cdot \mathrm{min}^{-1}$ under argon flow $\left(30 \mathrm{~mL} \cdot \mathrm{min}^{-1}\right)$.

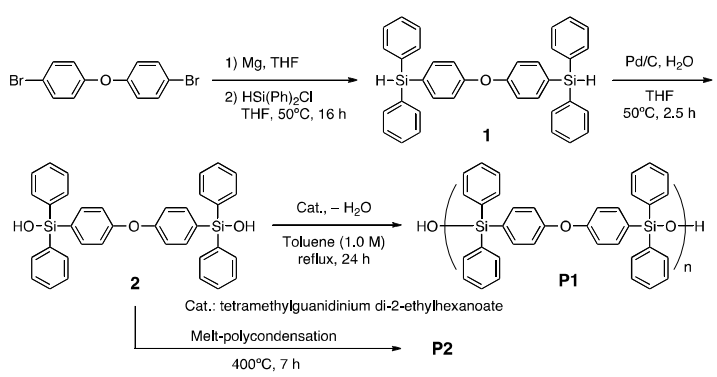

Scheme 1. Syntheses of polysilarylenesiloxanes.

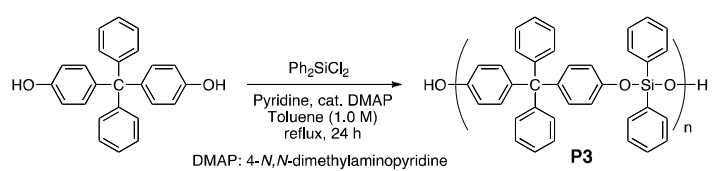

Scheme 2. Synthesis of polyaryleneoxysiloxane.

\section{RESULTS AND DISCUSSION}

3.1 Polysilarylenesiloxane (P1) polymerized in solvent

At first, polycondensation of $\mathbf{2}$ was conducted in 1,4-dioxane, xylene $(o-, m-, p$-mix. $)$, or toluene as polymerization solvent. As a result, the highest molecular weight of P1 was achieved when toluene was used. Reprecipitation purification of P1 was repeated by 7 times to remove a sub-product whose $M_{\mathrm{n}}$ nearly equaled to 1000 $\left(M_{\mathrm{w}} \cdot M_{\mathrm{n}}^{-1}=1.0\right)$ by GPC measurement. Probably, the sub-product would be a cyclic dimer of 2 .

3.2 Polysilarylenesiloxane (P2) prepared by melt-polycondensation

Melt-polycondensation was performed at 200, $250,300,350$ or $400^{\circ} \mathrm{C}$ for $2 \mathrm{~h}$ in an oven of TGA in order to decide the condition of melt-polycondensation. The results are shown in Table I. Molecular weight, $T_{\mathrm{g}}$ and the weight loss ratio, which calculated from the initial weight of monomer 2, increased with the increase of polymerization temperature. If perfect condensa- 
Table I. Results of melt-polycondensation of 2 at different temperatures.

\begin{tabular}{|c|c|c|c|c|}
\hline $\begin{array}{c}\text { Temperature } \\
\left({ }^{\circ} \mathrm{C}\right)\end{array}$ & $M_{\mathrm{n}} \cdot 10^{-3}$ a) & $M_{\mathrm{w}} \cdot M_{\mathrm{n}}^{-1}$ a) & $\begin{array}{l}\left.T_{\mathrm{g}} \mathrm{b}\right) \\
\left({ }^{\circ} \mathrm{C}\right)\end{array}$ & $\begin{array}{c}\left.\text { Weight loss }{ }^{\mathrm{c}}\right) \\
(\%)\end{array}$ \\
\hline 200 & 0.73 & 1.62 & 26.6 & 12.5 \\
\hline 250 & 1.42 & 1.81 & 38.4 & 15.4 \\
\hline 300 & 1.82 & 2.54 & 50.3 & 22.7 \\
\hline 350 & 2.30 & 2.67 & 56.1 & 31.6 \\
\hline 400 & 3.14 & 2.53 & 58.9 & 38.3 \\
\hline \multicolumn{5}{|c|}{$\begin{array}{l}\text { a) Determined by GPC measurement (PSt standard as a calibration, } \\
\text { THF as an eluent). } \\
\text { b) Determined by DSC on the second heating process under } \mathrm{N}_{2} \text {. } \\
\text { c) Weight loss ratio calculated from the initial weight of monomer } 2 \\
\text { after melt-polycondensation for } 2 \mathrm{~h} \text {. }\end{array}$} \\
\hline
\end{tabular}

tion reaction of 2 proceeded, the weight loss ratio was $3.2 \%$. We had reported that melt-polycondensation of a disilanol monomer proceeded with generating volatile compounds arising from degradation [7]. The volatile compounds generated during the melt-polycondensation were trapped to analyze them by means of GC-MS. As a result, the volatile compound was only one kind, whose molecular ion was $m / z=170$, and its fragment ions were $\mathrm{m} / \mathrm{z}=141,115$ and 110 . These fragment ions coincided with that of diphenyl ether $(\mathrm{FW}=$ 170). Considering $\mathbf{P 1}$ was stable below $400^{\circ} \mathrm{C}$ as mentioned later, condensation reaction and elimination reaction of diphenyl ether simultaneously took place in only the case that 2 and/or its oligomer were heated over their $T_{\mathrm{m}}$.

\subsection{Chemical structures of $\mathbf{P 1}$ and $\mathbf{P 2}$}

IR spectrum data of $\mathbf{P 1}$ and $\mathbf{P 2}$ as listed in the experimental part suggested that $\mathbf{P 2}$ possessed chemical structure which diphenyl ether moiety would be removed from $\mathbf{P 1}$.

${ }^{13} \mathrm{C}$-NMR spectra of $\mathbf{P 1}$ (a) and $\mathbf{P 2}$ prepared at $400^{\circ} \mathrm{C}$ for $2 \mathrm{~h}(\mathrm{~b})$ and $7 \mathrm{~h}$ (c) are shown in Fig. 1. Peak strengths of $\mathbf{e}, \mathbf{f}$ and $\mathbf{g}$ attributed to diphenyl ether moiety distinctly decreased during the melt-polycondensation, and new small peaks appeared at 117, 119,123,134, 156 and $159 \mathrm{ppm}$ in Fig. 1 (b) and (c). Peak intensity in the case of $7 \mathrm{~h}$ of polymerization time was larger than that of 2 h. Unfortunately, Fig.1 (c) was too complicate spectrum to reveal the chemical structure of $\mathbf{P 2}$.

\subsection{Polyaryleneoxysiloxane, $\mathbf{P 3}$}

Fig. 2 presented dependence of molecular weight of P3 against polymerization time under four kinds of conditions (in toluene at $100^{\circ} \mathrm{C}$, in toluene at refluxing temperature, in THF at $40^{\circ} \mathrm{C}$, and in chloroform at $40^{\circ} \mathrm{C}$ ). In toluene, the molecular weight of $\mathbf{P 3}$ increased with an increase of reaction time. On the other hand, the polycondensation in THF did not proceed successfully. In chloroform, molecular weight showed the highest value after $6 \mathrm{~h}$, and then decreased gradually. Si-O-C linkage within P3 would be easily hydrolyzed. To clarify the hydrolysis of $\mathbf{P 3}\left(M_{\mathrm{n}}=\right.$ $17.4 \times 10^{3}$, polymerized in toluene at $100^{\circ} \mathrm{C}$ for 24 $\mathrm{h})$, the reduction in $M_{\mathrm{n}}$ by additive was examined. The result was listed in Table II. P3 was easily

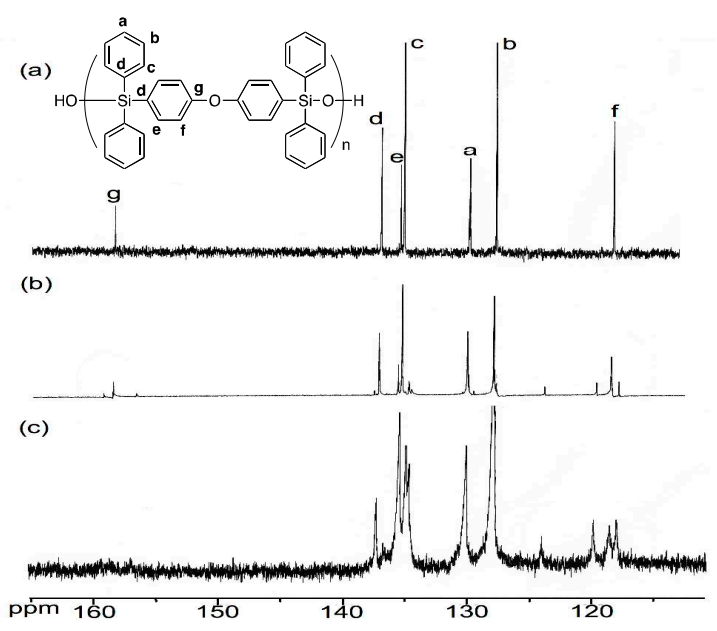

Fig. 1. ${ }^{13} \mathrm{C}-\mathrm{NMR}$ spectra of $\mathbf{P 1}$ and $\mathbf{P 2}$. (a) P1,

(b) $\mathbf{P 2}$ polymerized at $400^{\circ} \mathrm{C}$ for $2 \mathrm{~h}$, and (c)

P2 polymerized at $400^{\circ} \mathrm{C}$ for $7 \mathrm{~h}$.

hydrolyzed in entry $1-3$, which were treated by pyridine or pyridinium hydrochloride in homogeneous solution. However, P3 was stable without hydrolysis in dispersed solution of pyridinium hydrochloride (entry 4).

\subsection{Solubility of polymers}

The result of solubility test was presented in Table III. P1 and P3 showed better solubility than P2 which showed poor solubility in spite of low molecular weight. P2 would involve a slight amount of cross-linking structure arising from the elimination of diphenyl ether.

\subsection{Thermal properties of polymers}

TG curves of P1, P2 and $\mathbf{P 3}$ described in experimental part were drawn in Fig.4. P1 and $\mathbf{P 2}$ showed $529^{\circ} \mathrm{C}$ and $523^{\circ} \mathrm{C}$ of $T_{\mathrm{d} 5}$, respectively, and did excellent thermal stability similar to the fully aromatic polysilarylenesiloxanes in our previous

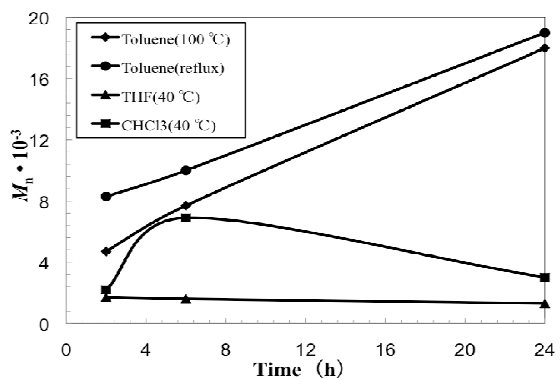

Fig.2. Molecular weights of $\mathbf{P 3}$ as function of polymerization time

Table II. Effect of additive on the reduction of molecular weight of P3.

\begin{tabular}{cccc}
\hline Entry & Solvent & Additive $^{\text {a) }}$ & $M_{\mathrm{n}} \cdot 10^{-3}$ a) \\
\hline 1 & Chloroform & $\mathrm{Py}$ & 2.02 \\
2 & Chloroform & $\mathrm{Py}^{+} \mathrm{Cl}^{-}$ & 6.81 \\
3 & Toulene & $\mathrm{Py}^{+}$ & 1.20 \\
4 & Toulene & $\mathrm{Py}^{+} \mathrm{Cl}^{-}$ & 16.4 \\
\hline
\end{tabular}

a) Pyridine (Py, $1 \mathrm{~mL})$ or pyridinium hydrochloride $\left(\mathrm{Py}^{+} \mathrm{Cl}^{-}, 50 \mathrm{mg}\right)$ as an additive was added to a mixture of $\mathbf{P 3}$ (initial $M_{\mathrm{n}}=17.4 \cdot 10^{3}$, $50 \mathrm{mg}$ ) in a solvent $(4 \mathrm{~mL})$. GPC measurement was conducted after stirring at room teperature for $4 \mathrm{~h}$. 
Table III. Solubility of polymers ${ }^{\text {a) }}$.

\begin{tabular}{ccccccc}
\hline Polymer & THF & $\mathrm{CHCl}_{3}$ & \multicolumn{5}{c}{ Toluene } & Acetone & $\mathrm{MeOH}$ & Hexane \\
\hline P1 & ++ & ++ & ++ & + & - & - \\
P2 & ++ & + & + & + & - & - \\
P3 & ++ & ++ & ++ & + & - & - \\
\hline
\end{tabular}

a) Each polymer $(10 \mathrm{mg})$ was added to a solvent $(0.1 \mathrm{~mL})$ and stirred at room temperature; ++: soluble, +: partially soluble, - : insoluble.

report [6, 7]. Although $\mathbf{P 2}$ had experienced unexpected large weight loss during the melt-polycondensation, the TG curve of obtained P2 almost coincided with that of P1. P3 also showed only a main degradation between 500 and $600^{\circ} \mathrm{C}$ just like $\mathbf{P 1}$ and $\mathbf{P 2}$, while a small weight loss was observed around $150^{\circ} \mathrm{C}\left(T_{\mathrm{d} 5}=493^{\circ} \mathrm{C}\right)$.

DSC curves of $\mathbf{P 1}, \mathbf{P 2}$ and $\mathbf{P 3}$ were drawn in Fig.5. P1 was a crystalline polymer, showing $334^{\circ} \mathrm{C}$ of $T_{\mathrm{m}}$, similar to the fully aromatic polysilarylenesiloxanes in our previous paper [6], but the crystallinity of $\mathbf{P 1}$ would be lower than that of them because $T_{\mathrm{g}}$ of $\mathbf{P 1}$ was clearly observed at $116^{\circ} \mathrm{C}$. On the contrary, $\mathbf{P 2}$ was an amorphous polymer, showing $93^{\circ} \mathrm{C}$ of $T_{\mathrm{g}}$ although the $T_{\mathrm{g}}$ was quite different from temperature and time of melt-polycondensation, as mentioned above (See Table I). P3 was also an amorphous polymer showing $137^{\circ} \mathrm{C}$ of the highest $T_{\mathrm{g}}$ in this paper.

\subsection{Optical property of polymers}

Fig.6 shows the absorbance spectrum of each polymer in chloroform by means of UV-Vis spectrometer. Expectedly, these polymer solutions were colorless and transparency against over 300

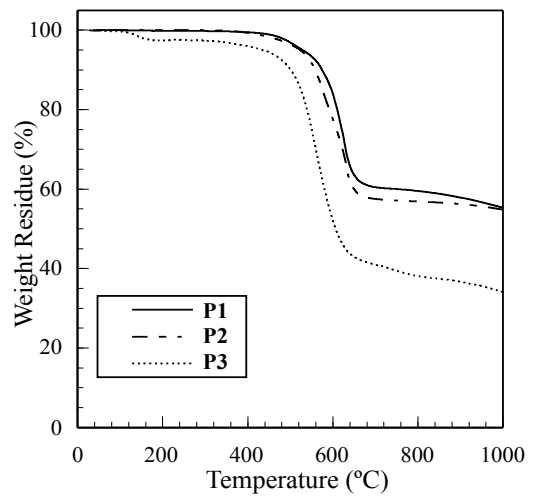

Fig.4. TG curves of polymers.

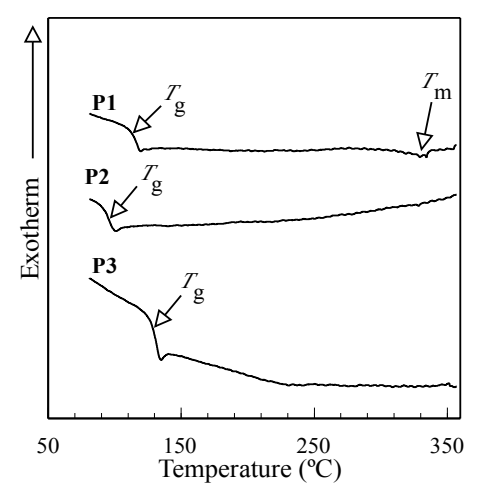

Fig.5. DSC curves of polymers (second heating processes).

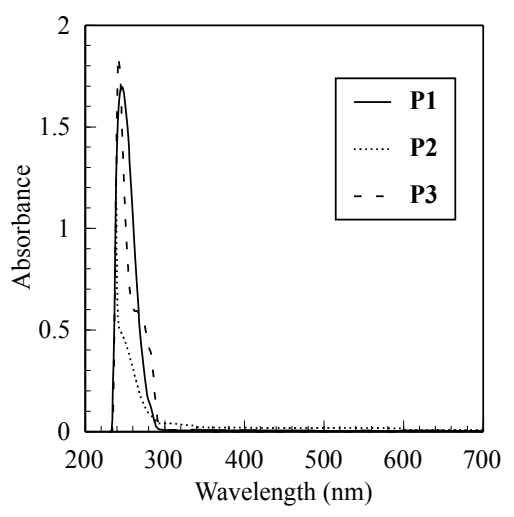

Fig.6. Absorbance of polymers in $\mathrm{CHCl}_{3}$ measured by UV-Vis spectrometer.

$\mathrm{nm}$ of a light, and exhibited $245 \mathrm{~nm}$ (P1), $239 \mathrm{~nm}$ (P2) and $242 \mathrm{~nm}$ (P3) of $\lambda_{\max }$. Wavelength of cut-off was $293 \mathrm{~cm}^{-1}$ for P1.

\section{CONCLUSIONS}

In this study, we aimed to achieve siliconcontaining polymers which were heat-resistant, soluble and transparent. Fully aromatic polysilarylenesiloxane having diphenyl ether moiety in a polymer-backbone, P1, was successfully prepared via polycondensation in a solvent. P1 was soluble in common solvents, very thermally stable, and transparent against visible light, but showed low crystallinity and not very high $T_{\mathrm{g}}$. P2 was obtained from the corresponding disilanol monomer for P1 via melt-polycondensation, which proceeded with elimination of diphenyl ether as sub-reaction to show amorphous and transparency. In addition, P2 was an oligomer, and would be too brittle to form a film. Polyaryleneoxysiloxane, P3, was also prepared from DTM and DDS, and showed the highest $T_{\mathrm{g}}$ in this study. However, P3 was easily hydrolyzed in homogeneous solution containing a base etc. P1 and $\mathbf{P 2}$ would be expected to apply to transparency high temperature coatings if their thermal mechanical stability were improved further.

\section{REFERENCES}

[1] P. R. Dvornic and R. W. Lenz, "High Temperature Siloxane Elastomers", Chapter III, Hüthig \& Wepf Verlag Basel/Heidelberg/New York (1990).

[2] R. L. Merker and M. J. Scott, J. Polym. Sci., A, 2, 15-29 (1964).

[3] N. Okui, H. M. Li, and J. H. Magill, Polymer, 19, 411-15 (1978).

[4] M. Ikeda, T. Nakamura, Y. Nagase, K. Ikeda, and Y. Sekine, J. Polym. Sci., Poly. Chem. Ed., 19, 2595-2607 (1981).

[5] R. L. Merker, M. J. Scott, and G. G. Haberland, J. Polym. Sci., A, 2, 31-44 (1964).

[6] H. Ito, E. Akiyama, Y. Nagase and S. Fukui, Polym. J., 38, 109-16 (2006).

[7] H. Ito, E. Akiyama, Y. Nagase and S. Fukui, Polym. J., 38, 1068-73 (2006).

[8] Y. Kawakami, Y. Sakuma, T. Wakuda, T. Nakai, M. Shirasaka and Y. Kabe, Organometal-lics, 29, 3281-88 (2010).

(Received Janurary 19, 2011; Accepted May 22, 2011) 